\title{
MICROSTRUCTURE AND MECHANICAL PROPERTIES OF AN AUSTENITIC STAINLESS STEEL SUBJECTED TO MULTIPLE FORGING AND SUBSEQUENT ANNEALING
}

\author{
Pavel DOLZHENKO, Selena GABOVA, Marina TIKHONOVA, Zhanna YANUSHKEVICH, \\ Andrey BELYAKOV, Rustam KAIBYSHEV
}

Belgorod State University, Belgorod, Russian Federation, dolzhenko.p@yandex.ru

https://doi.org/10.37904/metal.2019.865

\begin{abstract}
The present work is focused on studying the effect of multiple forging at room temperature and subsequent annealing on the microstructure and mechanical properties of a promising austenitic stainless steel with increased nitrogen content. An austenitic stainless steel, Fe-0.03C-22Cr-10Ni-0.36N-6.2Mn-0.34Si-1.9Mo (all in wt\%), with an average grain size of about $11 \mu \mathrm{m}$ was used as the initial material in the present study. The multiple forging was carried out by means of multi-pass compressions at room temperature to a total true strain of 2. The multiple forging was accompanied by deformation twinning and resulted in significant strengthening. Upon reaching the total strain of 2, the yield strength increased by $690 \mathrm{MPa}$, and the hardness increased by $210 \mathrm{HV}$. The steel samples subjected to multiple forging to a total strain of 2 were annealed for 30 minutes at temperatures of 773,873 and $973 \mathrm{~K}$. Annealing at temperatures of 773 and $873 \mathrm{~K}$ resulted in further strengthening, i.e., the yield strength increased to $1990 \mathrm{MPa}$ and $1940 \mathrm{MPa}$, the hardness increased to 614 $\mathrm{HV}$ and $588 \mathrm{HV}$, respectively. Annealing at a temperature of $973 \mathrm{~K}$ led to the formation of an equiaxial ultrafinegrained microstructure and a decrease in the yield strength and hardness to $1300 \mathrm{MPa}$ and $407 \mathrm{HV}$, respectively. The microstructural evolution during multiple forging and subsequent annealing and the structureproperty relationship are discussed in some detail.
\end{abstract}

Keywords: Forging, stainless steel, properties, microstructure

\section{INTRODUCTION}

Chromium-nickel austenitic stainless steels are the most promising candidates for crucial applications that are exploited under severe polar conditions [1]. Their main advantages are associated with a good corrosion resistance and high impact toughness even at low temperatures. This feature of austenitic stainless steels allows them to be used at low temperatures in seawater. A common drawback of austenitic stainless steels is their relatively low yield strength [2]. The well-known Hall-Petch relation states that the strength of metallic materials increases with a reduction in the grain size [3]. However, with conventional thermo-mechanical processing, it is quite difficult to obtain a homogeneous microstructure with a grain of less than 1 micron [4]. Therefore, the studies dealing with microstructure control in advanced metallic materials are of great practical importance. Increased yield strength can be achieved after severe plastic cold deformations [5,6]. However, the strengthening caused by cold working as a rule is accompanied by a degradation of ductility [7]. The most of developed methods of grain refinement are based on plastic deformation at ambient temperatures followed by annealing at elevated temperatures $[8,9]$. In this work, we studied the effect of severe plastic deformation by multiple forging at room temperature and subsequent annealing on the microstructure and mechanical properties of prospective austenitic steel that designated for use in harsh climatic conditions.

\section{EXPERIMENTAL}

An austenitic stainless steel, Fe-0.03C-22Cr-10Ni-0.36N-6.2Mg-0.34Si-1.9Mo (all in wt\%), was cast in the Central Research Institute for Machine-Building Technology, Moscow, Russia. The steel was annealed at 1373 $\mathrm{K}$ for $60 \mathrm{~min}$. followed by multiple forging at room temperature and subsequent annealing. The steel was 
characterized by the uniform initial microstructure with an average grain size of $11 \mu \mathrm{m}$. Prismatic samples with a dimensional ratio of 1.0:1.2:1.5 were subjected to multiple forging to a total strains of 2 . The multiple forging was carried out by means of multi-pass compression tests with a change of the loading direction in $90^{\circ}$ in order of three orthogonal axes i.e., $x$ to $y$ to $z$, etc., at room temperature. The compression tests were carried out at an initial strain rate of $10^{-3} \mathrm{~s}^{-1}$ using an Instron $300 \mathrm{LX}$ testing machine to a strain of 0.4 in each pass. The samples processed to a total strain of 2 were annealed at temperatures of 773,873 and $973 \mathrm{~K}$ for $30 \mathrm{~min}$.

The structural investigations were carried out using a Jeol JEM-2100 transmission electron microscope (TEM). To examine the phase content in the samples, X-ray diffraction (XRD) was studied using a Rigaku Ultima IV $\mathrm{X}$-Ray diffractometer. The operating voltage for the X-ray diffractometer was $40 \mathrm{kV}$, the current was $30 \mathrm{~mA}$ and the scanning range and step size were $35-100^{\circ}$ and $0.02^{\circ}$, respectively. The tensile tests of the flat-type specimens with $4 \mathrm{~mm}$ gauge length and $1.0 \mathrm{~mm}$ by $0.5 \mathrm{~mm}$ cross-section were carried out at room temperature and at an initial strain rate of $10^{-3} \mathrm{~s}^{-1}$ using an Instron 5882 testing machine.

\section{RESULTS AND DISCUSSION}

\subsection{Deformation behavior in the process of multiple forging}

Several true stress-strain curves for the five sequential forgings to a total strain of 2 at room temperature are shown in Figure 1a and a hardness measured on some specimens processed to various strains is shown in Figure 1b. Following the yielding at about $505 \mathrm{MPa}$, the first compression pass is characterized by gradual increase in the flow stress to about $1330 \mathrm{MPa}$, at the same time, hardness increases by 1.3 times. Upon further repeated deformation, the hardness increases to $553 \mathrm{HV}$, and the flow stresses saturates on the level of about $1400 \mathrm{MPa}$.
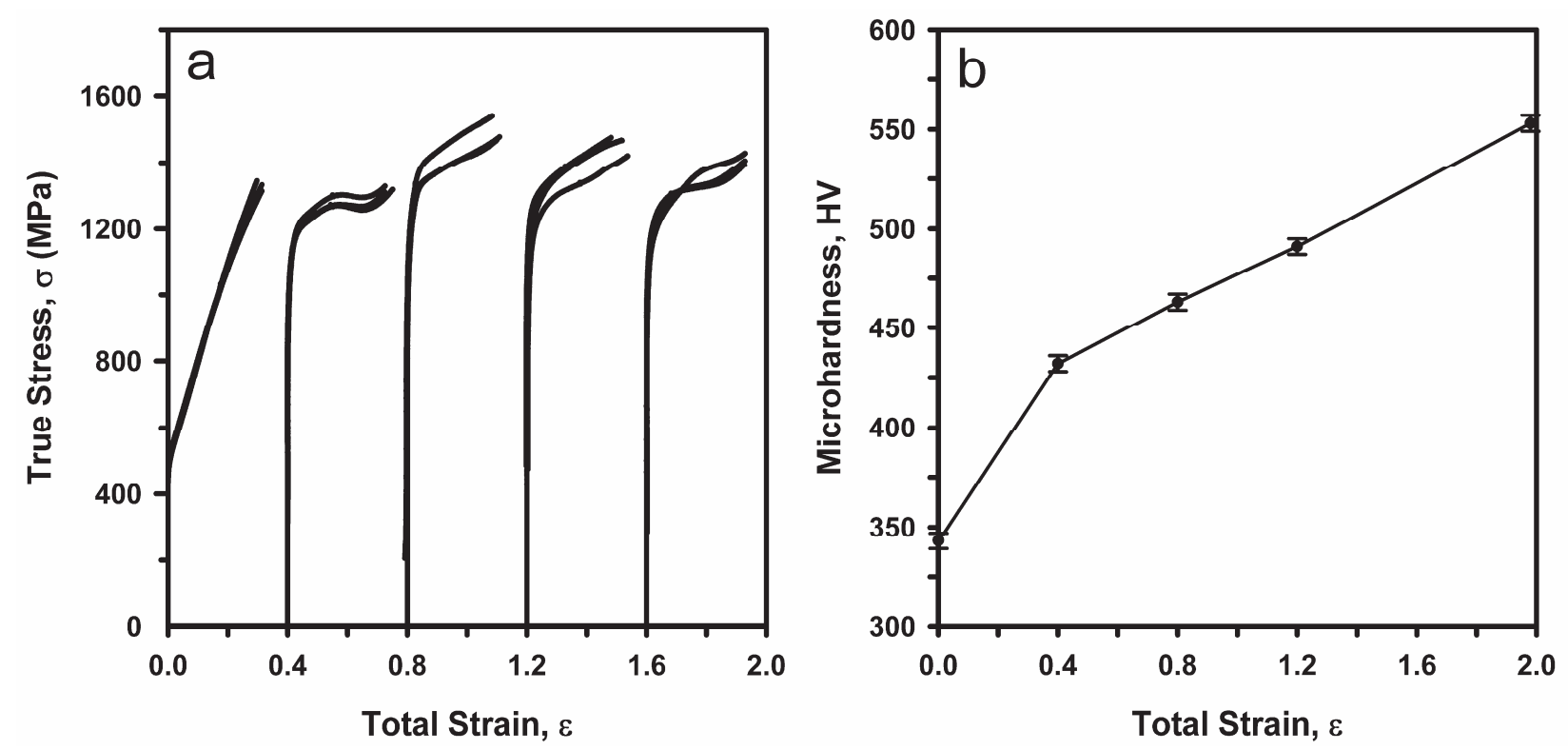

Figure 1 Stress-strain curves (a) and the strain effect on hardness (b) during multiple forging of an austenitic stainless steel

\subsection{Microstructure of austenitic steel}

The deformed microstructures that developed in the process of multiple forging austenitic steel to total strains of 0.4 and 2.0 are shown in Figure 2. The inhomogeneous microstructure consisting of deformation twins develops after the first forging pass (Figures 2a,b). It is clearly seen in Figure $2 \mathbf{a}$ that the main mechanism of grain subdivision at relatively small strains is associated with the mechanical twinning, which leads to the 
appearance of nanoscale structural elements outlined by high-angle boundaries. The subsequent change in the loading direction assists the formation of mutually crossed twins and, therefore, results in the development of spatial network of high- angle boundaries of deformation origin. An increase in the strain to 2 is also accompanied by mechanical twinning and, as a result, the refinement of structural elements (Figure 2c).
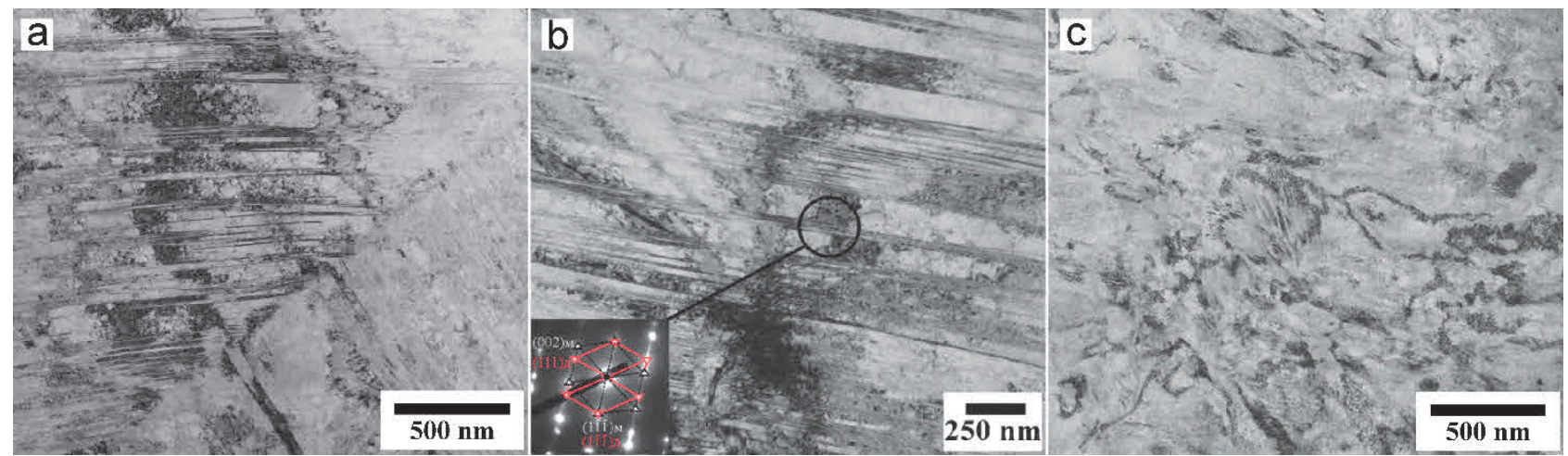

Figure 2 Typical TEM pictures of an austenitic stainless steel after multiple forging to total strains of $0.4(a, b)$ and 2 (c)

The microstructures of steel that obtained as a result of annealing at temperatures of $773 \mathrm{~K}$ and $973 \mathrm{~K}$ for 30 minutes are shown in Figure 3. Annealing at temperatures below $973 \mathrm{~K}$ does not led to remarkable changes in the deformation microstructure (Figure 3a). The microstructure of steel is still composed of mechanical twins. On X-ray diffraction (XRD) patterns obtained from the samples of austenitic steel after multiple forging and annealing at temperatures of $773 \mathrm{~K}$ and $873 \mathrm{~K}$, the peaks of varying intensity, which are characteristic of austenite, are observed (Figure 4). Annealing at temperature of $973 \mathrm{~K}$ (Figure 3b) leads to the formation of an ultrafine-grained microstructure with a grain size $250 \mathrm{~nm}$. In addition to the formation and growth of new grains during annealing at $973 \mathrm{~K}$, the intermetallic $\mathrm{FeCr}$ compound (sigma phase) precipitates. On the XRD patterns (Figure 4) of the austenitic steel sample after annealing at $973 \mathrm{~K}$, the peaks belonging to sigma phase appear.
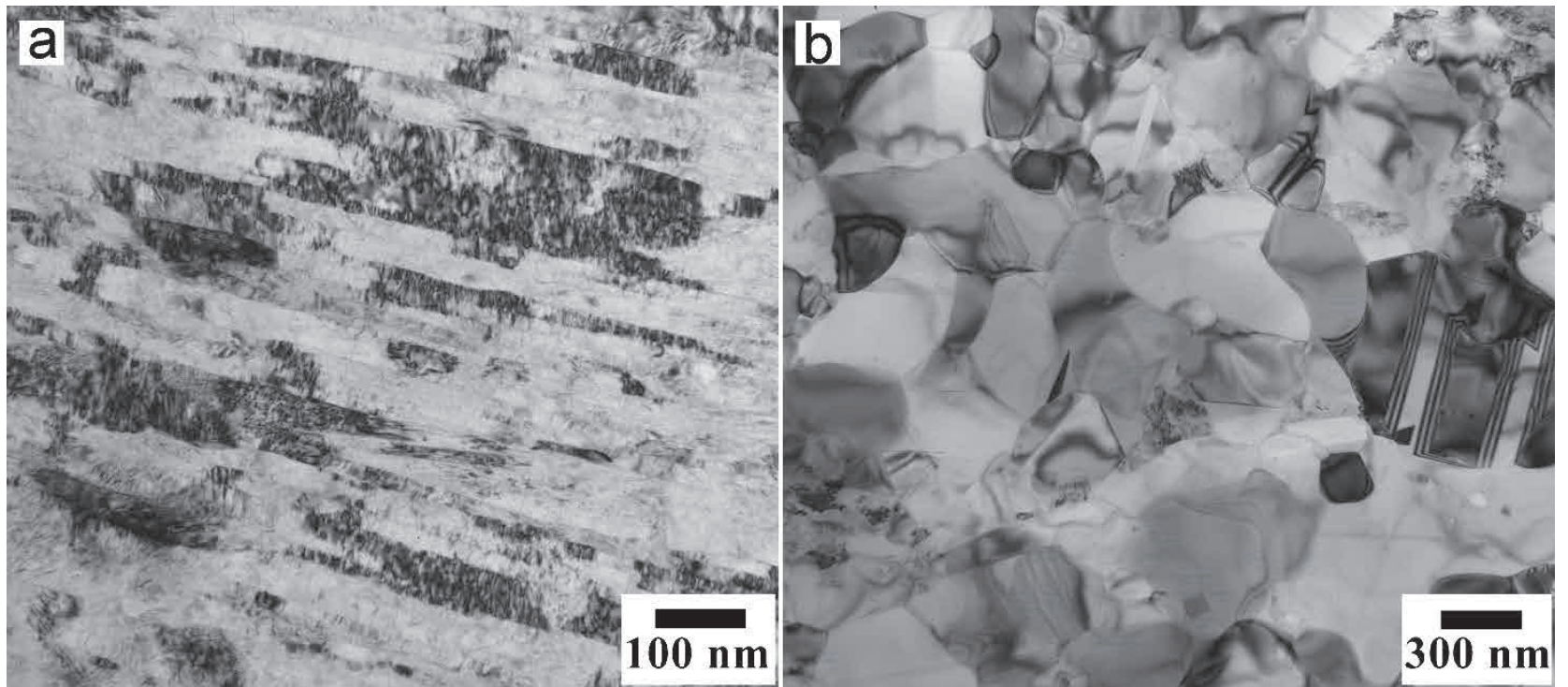

Figure 3 Typical TEM pictures of an austenitic stainless steel after multiple forging to total strains of 2 and annealing at $773 \mathrm{~K}(\mathrm{a})$ and $973 \mathrm{~K}(\mathrm{~b})$ 


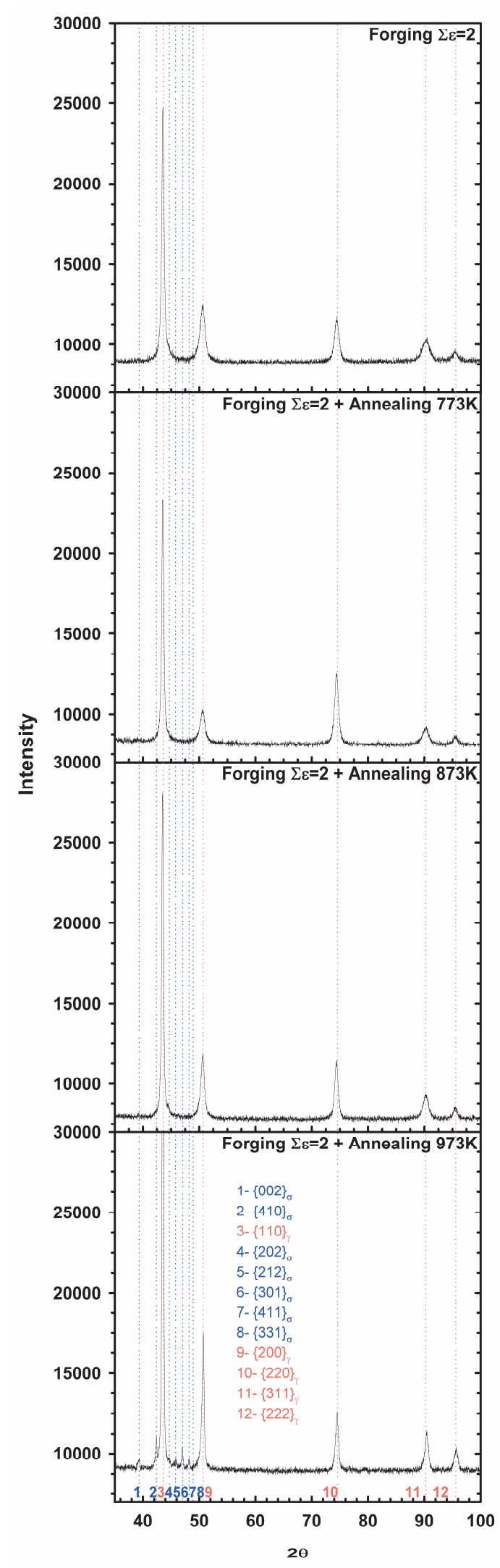

Figure 4 XRD patterns of an austenitic steel after cold forging and annealing at $773 \mathrm{~K}, 873 \mathrm{~K}$ and $923 \mathrm{~K}$ for 30 minutes

\subsection{Mechanical properties}

A series of engineering stress-elongation curves obtained during tensile tests at room temperature of the samples subjected to multiple forging to various total strains is shown in Figure 5. The multiple forging results in remarkable strengthening of the steel. The yield strength (YS) increases by 250 $\mathrm{MPa}$, and the ultimate tensile strength (UTS) increases by $230 \mathrm{MPa}$ after the first compression pass (the total strain of 0.4 ). Correspondingly, the strengthening is accompanied by a degradation of plasticity. The initial total elongation $(\delta)$ of about 33 $\%$ is almost halved to about $18 \%$ after the first compression pass. Further repeated forging to a total strain of $\varepsilon=2$ leads to an increase in the ultimate tensile strength to about $1800 \mathrm{MPa}$, and the yield strength is doubled to about $1580 \mathrm{MPa}$. On the other hand, the total elongation decreases from 33 to $9 \%$ as the number of compression passes increases to five.

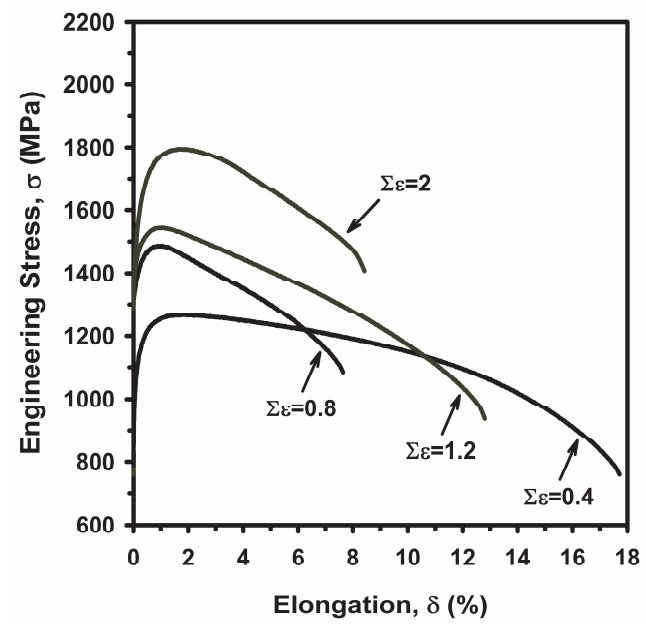

Figure 5 Tensile stress-elongation curves at room temperature for an austenitic stainless steel processed by multiple forging to various indicated total strains

A series of engineering stress-strain curves, obtained by tensile tests at room temperature for the steel samples subjected to multiple forging and annealing, is shown in Figure 6, and the tensile properties obtained are summarized in Table 1 along with initial steel sample. Annealing at temperatures of 773 and $873 \mathrm{~K}$ is not accompanied by a softening, but results in strengthening. 


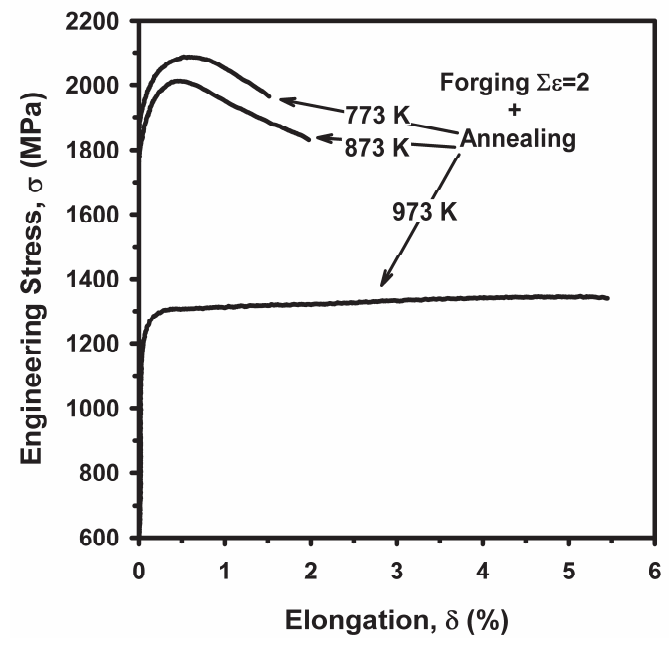

Figure 6 Tensile stress-elongation curves at room temperature for an austenitic stainless steel processed by multiple forging to total strain of 2 and annealing at indicated temperatures

The ultimate tensile strength of austenitic steel after annealing at $773 \mathrm{~K}$ increases to $2090 \mathrm{MPa}$, and the yield strength increases to $1990 \mathrm{MPa}$, while the elongation decreases to $1.6 \%$. The hardness increases by $270 \mathrm{HV}$ relative to the initial state, and by $60 \mathrm{HV}$ relative to the sample forged to a total strain of $\varepsilon=2$. An increase in the annealing temperature to $873 \mathrm{~K}$ leads to small hardening, the ultimate tensile strength increases to about $2010 \mathrm{MPa}$, and the yield strength increases to $1940 \mathrm{MPa}$ with a total elongation of $2 \%$. Annealing at a temperature of $973 \mathrm{~K}$ is accompanied by a remarkable softening. Ultimate tensile strength and yield strength reduce to 1340 and $1300 \mathrm{MPa}$, respectively, and the elongation comprises about $5 \%$. Microstructural investigations suggest that softening is associated with the process of static recrystallization, whereas sigma phase precipitation leads to embrittlement.

Table 1 Mechanical properties of the investigated austenitic steel after multiple forging and annealing for 30 minutes

\begin{tabular}{|c|l|c|c|c|c|}
\hline Property & Initial & $\Sigma \varepsilon=\mathbf{2}$ & $\Sigma \varepsilon=\mathbf{2 + 7 7 3 ~ K}$ & $\Sigma \varepsilon=\mathbf{2 + 8 7 3 ~ K}$ & $\Sigma \varepsilon=\mathbf{2 + 9 7 3}$ K \\
\hline UTS, Mpa & 1040 & 1800 & 2090 & 2010 & 1340 \\
\hline YS, Mpa & 890 & 1580 & 1990 & 1940 & 1300 \\
\hline Elongation, \% & 33 & 9 & 1.6 & 2 & 5.5 \\
\hline Microhardness, \pm 4 HV & 343 & 553 & 614 & 588 & 407 \\
\hline
\end{tabular}

\section{CONCLUSION}

The effect of multiple forging at room temperature and subsequent annealing on the microstructure and mechanical properties of an austenitic steel, Fe-0.03C-22Cr-10Ni-0.36N-6.2Mn-0.34Si-1.9Mo (all in wt\%), was investigated. The multiple forging results in remarkable strengthening of the steel. Multiple forging to a total strain of $\varepsilon=2$ leads to an increase in the yield strength to about $1580 \mathrm{MPa}$, the ultimate tensile strength to about $1800 \mathrm{MPa}$ while total elongation is $9 \%$. Annealing at temperatures of 773 and $873 \mathrm{~K}$ leads to further increase of the yield strength to 1990 and $1940 \mathrm{MPa}$, respectively with a decreased ductility of about $2 \%$ of total elongation. An increase in the annealing temperature to $973 \mathrm{~K}$ leads to the development of static recrystallization, which results in the formation of an ultrafine-grained microstructure with a grain size of 250 $\mathrm{nm}$. As a result of annealing, a decrease in the strength characteristics (UTS and YS) occurs, as well as a decrease in total elongation. The latter is associated with the formation of the sigma phase embrittling the 
steel. The results obtained can be useful in selecting the appropriate treatment in order to obtain an ultra-finegrained microstructure and improve mechanical properties.

\section{ACKNOWLEDGEMENTS}

The study was financially supported by the Russian Science Foundation, Project No. 17-72-10221. Authors are grateful to the staff of the Joint Research Center, "Technology and Materials", of the Belgorod State National Research University

\section{REFERENCES}

[1] LO, K.H., SHEK, CH.H. and LAI, J.K.L. Recent Developments in Stainless Steels. Materials Science and Engineering. 2009. vol. 65, pp. 39-104.

[2] MARTIENSSEN, W. and WARLIMONT, H. Springer Handbook of Condensed Matter and Materials Data. 1st ed. Berlin: Springer-Verlag Berlin Heidelberg, 2005. p.1119.

[3] BELYAKOV, A., TIKHONOVA, M., DOLZHENKO, P., SAKAI, T. and KAIBYSHEV, R. On kinetics of grain refinement and strengthening by dynamic recrystallization. Advanced Engineering Materials. 2018. vol. 27., pp. $125-131$.

[4] NAKAO, Y. and MIURA, H. Nano-Grain Evolution in Austenitic Stainless Steel during Multi-Directional Forging. Materials Science and Engineering. 2011. vol. 528 A, no. 3, pp. 1310-1317.

[5] TIKHONOVA, M., KUZMINOVA, Y., BELYAKOV, A. and KAIBYSHEV, R. Nanocrystalline S304H austenitic stainless steel processed by multiple forging. Reviews on Advanced Materials Science. 2012. vol. 31, pp. 68-73.

[6] VALIEV, R..Z., ISLAMGALIEV, R.K., and ALEXANDROV, I.V. Bulk nanostructured materials from severe plastic deformation. Progress in Materials Science. 2000. vol. 45, pp. 103-89.

[7] TIKHONOVA, M., KAIBYSHEV, R., and BELYAKOV, A.. Microstructure and Mechanical Properties of Austenitic Stainless Steels after Dynamic and Post-Dynamic Recrystallization Treatment. Advanced Engineering Materials. 2018. vol. 20, no. 7, pp. 1-27.

[8] ZHEREBTSOV, S.V., DYAKONOV, G.S., SALEM, A.A., MALYSHEVA, S.P., SALISHCHEV, G.A. and SEMIATIN, S.L. Evolution of grain and subgrain structure during cold rolling of commercial-purity titanium. Materials Science and Engineering. 2011. vol. 528A, pp. 3474-3479.

[9] ROLLETT, A.D., HUMPHREYS, F.J., ROHRER, G.S. and HATHERLY, M. Recrystallization and related annealing phenomena. 2nd ed. Oxford: Elsevier, 2004. p. 628. 